\title{
O percurso da sustentabilidade do desenvolvimento: aspectos históricos, políticos e sociais
}

The road to sustainable development: historical, political and social aspects

\author{
Sandro Haoxovell de Lira' ; Therezinha de Jesus Pinto Fraxe ${ }^{2}$ \\ ' Doutorando do Programa de Pós-graduação em Ciências do Ambiente e Sustentabilidade na Amazônia (PPGCASA-UFAM). Técnico-ad- \\ ministrativo em Educação do Instituto de Saúde e Biotecnologia de Coari-AM (ISB-UFAM) - AM - Brasil \\ ${ }^{2}$ Doutora em Sociologia. Professora Associada da Universidade Federal do Amazonas, \\ coordenadora do Núcleo de Socioeconomia (NUSEC-FCA-UFAM) e coordenadora do Programa de Pós-Graduação em \\ Ciências do Ambiente e Sustentabilidade na Amazônia (PPGCASA-UFAM) - AM - Brasil
}

\begin{abstract}
Resumo
O presente artigo objetiva realizar uma revisão teórica sobre os principais acontecimentos que culminaram na gênese da consciência ambiental no mundo moderno. Assim, faz um conciso resgate histórico e político das conferências intergovernamentais sob os auspícios da ONU desde 1970, passando pela Conferência de Estocolmo, Rio-92 e, por fim, a recente Rio+20. Além disso, aponta os principais entraves, desafios e contradições impostos à consecução da sustentabilidade como propósito planetário. A compreensão dos processos que culminaram no surgimento da problemática ambiental em nível global, a partir da historicidade da sustentabilidade, assim como as medidas adotadas para enfrentamento da crise socioambiental, representa um passo fundamental a todo pesquisador da área, a fim de se evitar enfoques imprecisos da questão. Trata-se de uma leitura necessária aos que adentram nas discussões sobre a sustentabilidade do desenvolvimento, quer nos níveis local, regional, nacional ou mundial. Entender criticamente os processos históricos, políticos e sociais da sustentabilidade possibilitará ultrapassar uma visão fragilizada, míope e equívoca na análise, abordagem e tratamento das mazelas socioambientais na modernidade. Palavras-Chaves: Desenvolvimento sustentável. Consciência ambiental. Trajetória histórica. Degradação ambiental.
\end{abstract}

Palavras-chave: Desenvolvimento sustentável, conservação de recursos hídricos, reuso de água, água pluvial, água cinza.

\begin{abstract}
This article objectives to realize a theoretical review about the principal events that led to the genesis of environmental consciousness in the modern world. So, does a concise historical and political research about the intergovernmental conference under UN auspices since 1970 , going through the Stockholm Conference, Rio-92, and finally, the recent Rio+20. Moreover, points out the main obstacles, challenges and contradictions imposed to the achieving of the sustainability as planetary purpose. The understanding of the processes that culminated in the emergence of environmental issues on a global level, from the historicity of sustainability, as well as the measures taken to cope the environmental crisis is a crucial step to any researcher in the field, in order to avoid the inaccurate approaches question. This is a required reading for the ones who enters in discussions about the sustainability of development, whether at the local, regional, national or global. Critically understand the historical, political and social processes of the sustainability will enable to overcome a weakened vision, myopic and misleading in the analysis, evaluation and treatment of environmental ills of modernity.
\end{abstract}

Keywords: Sustainable development. Environmental awareness. Historical trajectory. Environmental degradation. 


\section{INTRODUCC̃̃O}

Para propiciar um melhor entendimento do conceito de sustentabilidade do desenvolvimento e sua vinculação com o processo de exploração de recursos ambientais e a degradação humano-cultural global, torna-se imprescindível, primeiramente, rememorar todo o processo sociopolítico que abarca a construção e discussão da sustentabilidade, bem como sua trajetória histórica.

A gênese da noção de sustentabilidade refere-se à expansão da hegemonia europeia nos continentes asiático, africano e americano. Esse processo não representa um marco na atenção às necessidades humano-culturais e ecológicas dos países periféricos, mas é marcada por crescimento desigual, célere degradação ambiental, desumanização dos espaços, destruição de memórias e histórias dos lugares, denominações depreciativas em relação às nações precarizadas, fundadas por ideologias binárias (Norte-Sul, Desenvolvido-Subdesenvolvido, Responsável-Irresponsável, Central -Periférico), etnocentralizadas e discriminatórias, demarcando a linha divisória entre os beneficiários e não-beneficiários da globalização (FREITAS, 2003). O nascedouro da sustentabilidade ocorre na conjuntura da globalização a partir de um limite e símbolo que se propõe a reorientar o processo civilizacional da humanidade, de modo a questionar a racionalidade e parâmetros que sustentam e estabelecem o crescimento unimodal econômico, rejeitador dos processos ecológicos (LEFF, 2005) e humano-culturais.

Já segundo Nascimento (2012), a noção da sustentabilidade origina-se de duas esferas: da biologia, por intermédio da ecologia, e da economia. Quanto à primeira, alude à capacidade de regeneração e reprodução dos sistemas ecológicos (resiliência) diante das perturbações antropogênicas (no uso excessivo dos bens naturais, desmatamento, fogos, dentre outros) ou ecológicas (terremoto, tsunami, fogo e outros). Em relação à segunda noção, refere-se à adjetivação de desenvolvimento, diante da percepção no decorrer do Século XX de que o paradigma produtivo e de consumo em larga expansão não pode persistir. Para isso, surge a sustentabilidade sob a ótica da limitação dos recursos ecológicos e sua gradual e ameaçadora redução. Esse entendimento palmilhou uma longa trajetória histórica até chegar o que é hoje e as suas origens mais recentes foram germinadas na década de 1950 quando a humanidade percebe o risco ecológico planetário, a saber, a poluição nuclear. Entre 1953 e 1965 os efeitos secundários do DDT e outros pesticidas provocaram nos EUA significativas mortes de aves em várias regiões, sendo estes e outros fatos divulgados pela imprensa os responsáveis pelo surgimento de preocupações com o futuro da humanidade.

A temática da sustentabilidade ganha, pois, centralidade desde o final do Século XX e da passagem para o Terceiro Milênio, que é a passagem da modernidade mutilada e não concluída para uma pós-modernidade de incertezas, caracterizada pela diferenciação, pela diversidade, democracia e pela autonomia, tecnologização da vida e da natureza economizada. (LEFF, 2005). As retóricas políticas das últimas décadas do Século XX e, sobretudo, a contar da gênese Terceiro Milênio, possibilitaram a conclusão do pensamento de que a proteção ao meio ambiente representa um problema fortemente vinculado com a ideação de futuro melhor e mais promissor para a humanidade. Esse pensamento existe desde os primeiros arautos alertantes do crescimento populacional e foi se fortalecendo por significativas pressões sobre os recursos ambientais há quatro décadas, o que possibilitou a adesão crescente de atores societários nesse campo sociopolítico de luta (BURSZTYN e BURSZTYN, 2006).

A questão ambiental se impôs na agenda política e econômica internacional como tema central em face do risco de depleção dos recursos ecológicos e da biodiversidade e da degradação da condição humana, como um sintoma da crise civilizacional, razão pela qual conserva toda sua pertinência e relevância na modernidade para todos os campos do conhecimento científico.

\section{PROCEDIMENTOS METODOLÓGICOS}

Trata-se de uma revisão bibliográfica e utiliza da pesquisa em literatura especializada em autores que discutem os processos históricos da sustentabilidade global, bem como estudam e analisam os principais aspectos sobre a problemática socioambiental e suas principais contradições e entraves à consecução da sustentabilidade do desenvolvimento planetário.

\section{RESULTADOS E DISCUSSÕES}

\section{I. A inclusão da sustentabilidade na agenda econômica e política mundial}

Apesar das preocupações ambientais na modernidade se iniciarem na década de 50 do século passado, é somente em 1960 que o movimento de inquietação e consciência ambiental no 
nível global ganha destaque. Mesmo assim, ocorreram diferentes percepções e formas de enfrentamento da questão ecológica. Nos países centrais, a ênfase foi dada ao controle e regulação de substâncias contaminantes advindas dos altos níveis de produção e consumo de mercadorias. As versões mais críticas das políticas ambientais nesses países tinham caráter apenas instrumental, com intuito de apenas controlar as consequências provenientes do modelo de desenvolvimento em curso para uma refuncionalização ambiental. Já nos países empobrecidos do Terceiro-Mundo, em especial os tropicais, visualiza-se um contexto complexo e ampliado no processo de desenvolvimento, onde a questão ambiental requer além do controle de contaminação e seus custos econômicos, havendo nesses países potenciais prospecções para uma estratégia do desenvolvimento sustentável diferente da que temos hoje (LEFF, 2000).

A partir dos anos de 1960, vários documentos como a "Tragedy of the Commons" de Hardin (1968), "The population bomb" de Ehrlich (1968) (KITAMURA, 1994), e na década de 1970 ocorre a Convenção de Bruxelas a respeito da constituição de um fundo internacional de indenização por danos devidos à contaminação por hidrocarburos (1971), a Convenção de Ramsar sobre a conservação de zonas úmidas de relevância internacional (1971), a Convenção de Londres, cujo fito foi a proteção das focas da Antártida (1972) (MAIA FILHO, 2010), o documento "Blueprint for survival" editado pela revista The ecologist (1972) e "Os limites do crescimento", conhecido também por Relatório do Clube de Roma ou do Massachussets Institute of Technology, do professor Denis Meedows et al (1972) explicitam as ênfases das discussões tomadas (KITAMURA, 1994).

Em 1970 os pensamentos de Ehrlich ganham notoriedade, a partir dos quais se cria que nos anos de 1970 e 1980 enormes contingentes populacionais morreriam de fome em função da superpopulação. Defendia o teórico, bem como outros sobrevivencialistas, dessa feita, práticas marcadas por autoritarismo e centralizadorismo, como especificamente o estabelecimento de limites ao crescimento populacional (WENCESLAU, ANTEZANA e CALMON, 2012). As discussões desse período estavam fortemente influenciadas pela experiência dos países industrializados, privilegiando os danos sobre o ambiente biofísico, em detrimento do estudo das questões socioeconômicas relacionadas aos problemas ambientais. Duas questões merecem destaque nesse período: o aumento constante da demanda por matérias-primas e de energia nos países industrializados e a explosão demográfica nos países em desenvolvimento. Apesar disso, a consciência ambiental só emerge com a obra de Rachel Carson, Primavera Silenciosa, nos anos de 1960, e ganha força nos anos 1970, a partir da Conferência de Estocolmo (LEFF, 2005).

Sobre as publicações, o relatório do Clube de Roma, especialmente, prepara o pano de fundo para a Conferência das Nações Unidas sobre o Meio Ambiente Humano ocorrida em 1972, em Estocolmo (BURSZTYN e BURSZTYN, 2006), que significou o primeiro passo a fim de discutir e resolver a problemática ambiental e institucionalizar a questão na agenda política em nível internacional (WENCESLAU, ANTEZANA e CALMON, 2012).

Em síntese, pode-se dizer que esse período de discussões foi marcado pela preocupação mais global acerca dos problemas ambientais, apesar das diferenças ideopolíticas existentes entre as nações. A Conferência de Estocolmo, Suécia, como marco da moderna formulação da questão do meio ambiente global e como objeto de políticas públicas, é realizada sob a influência do Relatório do Clube de Roma. Sendo que o foco das discussões naquele momento era o meio ambiente humano (BURSZTYN e BURSZTYN, 2006). Nesta conferência, ficou claro que a ideia do desenvolvimento econômico era inconciliável com a conservação do meio ambiente, bem como: 1) a proteção do meio ambiente já estava majoritariamente prejudicando o bem-estar humano e os processos de desenvolvimento econômico; 2) o crescimento natural das populações humanas coloca em xeque a preservação ambiental; 3) os problemas ambientais mais importantes dos países do Norte eram os de poluição ambiental e dos países do Sul eram o uso inadequado e o esgotamento da base de recursos ecológicos (KITAMURA, 1994). Em outras palavras, é na Conferência de Estocolmo que são salientados os limites da razão econômica e os desafios da degradação ecológica ao projeto civilizacional da sociedade moderna (LEFF, 2005), pondo o campo ambiental na agenda internacional (SACHS, 2008). Era o começo de uma difícil etapa de negociações e discussões internacionais, de um lado, acerca dos riscos ao meio ambiente e, de outro, da adoção de papeis de diferentes nações (BURSZTYN e BURSZTYN, 2006).

Dois trabalhos e um evento vão causar impactos sobre o terreno da sustentabilidade, embora não tenham influência sobre a Reunião de Estocolmo, terão influência sobre a reflexão da economia: o primeiro em 1971, de Georgescu-Roegen (1999), que trata da economia como 
subsistema da ecologia, baseado na entropia; o outro trabalho é de Arne Naess (1973), publicado na revista Inquiry, tornando-se celeremente o estandarte dos ambientalistas mais radicais, com a diferenciação da ecologia superficial (preocupação com a poluição nos países ricos) e ecologia profunda (preocupação com problemas ecológicos em todo o mundo); e a primeira crise do petróleo de 1973 (NASCIMENTO, 2012).

Os anos seguintes marcados pelo primeiro grande choque do petróleo de 1973-1974 fizeram com que as previsões do Clube de Roma e de outros documentos fossem concretizadas pela falta da principal fonte de energia global, cujos impactos foram severos nas economias dos países (KITAMURA, 1994; BURSZTYN e BURSZTYN, 2006). Essa realidade evidenciou outra questão não menos importante: a necessidade de cooperação internacional entre as nações, em função das interdependências entre as economias mundiais. (KITAMURA, 1994). A contraditoriedade desse período ocorre da seguinte forma: diversos países começam a adotar mecanismos de regulação dentro dos limites geográficos nacionais, apesar de haver tímidas preocupações com as questões ambientais globais, na prática suas políticas ambientais foram meramente nacionais (BURSZTYN e BURSZTYN, 2006). Os governos, então, começam a se mobilizar para a construção de agências de atenção das questões ambientais, tais como nos Estados Unidos foi criada a Environmental Protection Agency (EPA), e no Brasil se cria a Secretaria Especial do Meio Ambiente (SEMA), em 1973 (BURSZTYN e BURSZTYN, 2006; NASCIMENTO, 2012).

A segunda crise do petróleo de 1979, e mais tarde no início dos anos 1980, consequentemente, marcada pela alta dos preços do barril de petróleo, a crise econômica global e a crise da dívida externa dos países não industrializados minaram as prospecções de cooperação entre Norte-Sul. Os países ricos detinham-se a tentar escapar do gargalo da recessão às suas economias, não restando atenções e apoio aos países mais precarizados (KITAMURA, 1994). As duas crises do petróleo na década de 1970 evidenciaram o quão frágil é a economia industrial capitalista e mostrou, ainda, outro tipo de inquietação vinculada à ameaça do paradigma econômico em razão da depleção progressiva dos recursos ambientais do mundo, bem como esse processo pode comprometer a sustentabilidade socioambiental planetária.

Em 1979, foi realizada a Convenção de Berna, um instrumento chave sobre a conservação da vida selvagem e do meio natural na Europa, assinada pelo Conselho da Europa (SILVA, 2009) e a Convenção de Genebra, no mesmo ano, que instituiu o quadro europeu de cooperação em matéria de poluição atmosférica de longa distância (SILVA e DIAS, 2012).

Na década seguinte, em 1982, a UNEP realiza a Conferência de Nairóbi, ocasião em que se deliberou pela criação da Comissão Mundial sobre Meio Ambiente e Desenvolvimento (ONU), cuja presidência foi exercida pela primeira ministra da Noruega, Gro Harlem Brundtland. Como resultado desta comissão, foi publicado em 1987 o relatório "Nosso Futuro Comum", conhecido também como Relatório de Brundtland, em várias línguas (ROMEIRO, 2012).

Vale lembrar que a Comissão Mundial sobre Meio Ambiente e Desenvolvimento foi criada em 1984 a fim de realizar avaliação dos avanços da degradação ambiental e a eficácia das políticas ambientais para o seu enfrentamento. E após 3 anos de pesquisas, deliberações e audiências públicas, a comissão publicou o Nosso Futuro Comum, conhecido também como Relatório Brundtland ou Informe Brundtland (LEFF, 2005). É nesse contexto que se divulgou a definição do desenvolvimento sustentável, por intermédio do livro Nosso Futuro Comum, que foi considerado um marco formal dessa mudança de atitude, a saber, "[...] aquele que atende às necessidades do presente sem comprometer a possibilidade de as gerações futuras atenderem a suas próprias necessidades" (CMMAD, 1991, p. 46).

A definição do relatório apresenta duas faces, sendo uma de força e outra de fraqueza. Fraca, pois apresenta uma forma vaga sem determinar quais seriam as necessidades humanas atuais e as futuras. Forte porque insere a intergeracionalidade no conceito de sustentabilidade, vinculando-a à noção de justiça social, que seria o declínio das disparidades societais e direito de acesso aos bens e serviços indispensáveis a uma vida digna, e aos valores éticos, que são o compromisso com as gerações vindouras (NASCIMENTO, 2012).

É, pois, em 1987 quando foi divulgado "Relatório de Brundtland", fruto dos trabalhos da Comissão Mundial para o Meio Ambiente e Desenvolvimento (CMMAD) das Nações Unidas que surge uma visão mais globalizante e transnacional dos problemas ecológicos. Este documento denuncia a insustentabilidade dos paradigmas de desenvolvimento econômico vigente, explorando e degradando os recursos ecossistêmicos, pondo em risco a própria possibilidade vindoura de desenvolvimento. Outras questões relevantes relatadas são que a pobreza, a ausência de desenvolvimento e superpopulação humana têm vinculações muito 
estreitas com as questões ambientais globais.

O Informe Brundtland confirma as dissemelhanças e desigualdades entre os países e o modo como essas se exacerbam com a crise da dívida externa dos países do Sul. Também persegue consenso político para suprimir as diferenças de ótica e interesses particulares de países, povos e classes societais, presentes no campo de conflito da sustentabilidade. Nesse processo, inicia a configuração de tática política para a sustentabilidade ecológica da globalização como condição de sobrevivência humana em nível global, por meio de cooperação conjunta de todas as nações (LEFF, 2005). Destaca-se que o "Relatório de Brundtland" consegue, dentre outras coisas, dar notoriedade mundial ao termo desenvolvimento sustentável, colocandose a necessidade urgente de revisão dos modelos econômicos de desenvolvimento, que deveriam passar a basear-se num outro modelo, a saber, o desenvolvimento sustentável, colocando uma visão antropocêntrica e negando o ecocentrismo. Para isso, tornam-se fundamentais ações conjuntas e abrangentes de países desenvolvidos e países em desenvolvimento, que ultrapassem o estreitismo biofísico, incluindo aspectos socioeconômicos e suas inter-relações nas questões ecológicas.

Em fins da década de 1980 (1989) a convocação da Conferência das Nações Unidas para o Meio Ambiente e Desenvolvimento (CNUMAD) para 1992 foi aprovada pela Assembleia das Nações Unidas. O evento mais tarde ficou conhecido como a Rio-92 ou Eco-92.

A década de 1990 foi fortemente marcada pelo receituário e empreitada neoliberal, pelo aprofundamento das desigualdades sociais intra e internacional, a crescente preocupação acerca da qualidade ambiental, aceleração dos processos de expansão agrícolas, industrialização e urbanização não planejada, questões climáticas, contaminação hídrica e a perda da biodiversidade, enfim, a degradação socioambiental global, que conspirou contra a governança mundial (RODRIGUES FILHO et al., 2009). Este cenário mundial foi o palco para a Conferência das Nações Unidas sobre o Meio Ambiente e Desenvolvimento, realizada no Rio de Janeiro, que contou com a presença de 178 países. Neste evento, foram aprovados alguns documentos, dos quais se destaca cinco: Declaração do Rio de Janeiro, Agenda 21, Convenção sobre biodiversidade, Convenção sobre alterações climáticas e Declaração sobre florestas. Conforme Nascimento (2012, p. 55), "[...] os efeitos mais visíveis foram a criação da Convenção da Biodiversidade e das Mudanças Climáticas - que resultou no Protocolo de Kyoto -, a Declaração do Rio e a Agenda 21". Particularmente sobre a Agenda 21 , trata-se de um programa de cunho mundial instituído para regulamentar o desenvolvimento fundado nos princípios da sustentabilidade. Assim foi se prefigurando uma política para a mudança global a fim de suprimir os antagonismos havidos entre ambiente e processos de desenvolvimento (LEFF, 2005).

Naquela ocasião, as atenções se prenderam ao meio ambiente e aos processos de desenvolvimento, como se percebeu nos discursos sobre a conciliação entre qualidade ambiental e o paradigma de desenvolvimento da economia. Além disso, a Eco-92 ratificou a disseminação e consolidou o conceito de desenvolvimento sustentável, que contou maciçamente com a colaboração dos instrumentos midiáticos. Assim, "O discurso do desenvolvimento sustentável foi sendo legitimado, oficializado e difundido amplamente com base na Conferência das Nações Unidas sobre o Meio Ambiente, celebrada no Rio de Janeiro, em 1992" (LEFF, 2005, p. 16). Em outras palavras, as atenções se prendem à relação entre qualidade ambiental e modelo de crescimento da economia ou meio ambiente e desenvolvimento (BURSZTYN e BURSZTYN, 2006).

Todavia, uma grande confusão ocorreu, pois se acreditava ilusoriamente que todos os males societários e ambientais seriam resolvidos uma vez evocado o desenvolvimento sustentável. Neste cenário, a Rio-92 constituiu-se num marco internacional relevante para a confirmação de compromissos dos governantes quanto ao desenvolvimento sustentável. Evidentemente, as divergências políticas e conflitos decorrentes de interesses econômicos não trouxeram o cumprimento dos acordos no patamar esperado e necessário.

Resumindo, pode-se dizer que nas duas principais conferências - de Estocolmo (1972) e Rio (1992) - surge a ideia de que o desenvolvimento possui, além de uma face de depreciação ecológica, um aspecto societário inerente. Haja vista que a pauperização é causadora de agressões ambientais e, por isso, a sustentabilidade deve contemplar a equidade social e a qualidade de vida das gerações atuais e das próximas. A solidariedade com as próximas gerações introduz, de forma transversal, a dimensão ética (NASCIMENTO, 2012).

Dez anos mais tarde, 2002, ocorre em Johanesburgo, na África do Sul, a

[...] Cúpula Mundial sobre Desenvolvimento Sustentável ou Cúpula da Terra 2 (Rio +10$)$, com o objetivo de realizar um balanço dos compromisso firmados na Rio 
92. Ficou claro que, apesar das intenções manifestadas na Rio 92, houve no período decorrido entre as duas conferências uma piora nos indicadores socioambientais e uma redução percentual da ajuda dos países ricos ao desenvolvimento dos países pobres. [...] a Conferência de Johanesburgo concentrou-se no objetivo prioritário da redução da pobreza, adquirindo assim um caráter marcadamente socioambiental (JOTABÁ, CIDADE e VARGAS, 2009, p. 59).

No evento, chegou-se à conclusão de que houve pouca evolução nos países signatários da Agenda 21 em relação às Políticas Públicas, evidenciando que pouco se avançou na preservação do ambiente e na sustentabilidade do desenvolvimento. A solidariedade entre as nações anunciada na Eco92 não se concretizou na medida esperada. E diante do agravamento das desigualdades econômicas entre países e grupos societários no mundo, em face da pobreza humana, a ênfase das discussões de Johanesburgo foi dada ao enfrentamento da pobreza e menor atenção em relação ao meio ambiente natural (BURSZTYN e BURSZTYN, 2006).

[...] muito pouco foi efetivamente realizado após a Rio +10 . As inúmeras conferências sobre mudanças climáticas (COPs) e outros encontros realizados para discutir problemas como o aquecimento global, aumento da desertificação, perda da biodiversidade, impactos ambientais em populações vulneráveis, apresentaram poucos avanços (WENCESLAU, ANTEZANA e CALMON, 2012, p. 596).

Vinte anos depois da Conferência Rio92, a Rio+20 foi realizada com a finalidade de suplantar o impasse dos anos anteriores e definir a agenda ambiental para os próximos decênios. Nomeadamente, o objetivo foi o de revigorar o comprometimento político com o desenvolvimento sustentável, de modo a avaliar o progresso e as brechas na implementação da agenda ambiental, e ainda discutir e tratar novas e emergentes temáticas. Como fruto da Rio+20 temos o relatório "The Future We Want" (WENCESLAU, ANTEZANA e CALMON, 2012). Em sua análise comparada do discurso entre "The future we want" da Rio+20 e as retóricas ambientais prévias à conferência, Wenceslau, Antezana e Calmon (2012) sinalizam que o primeiro está baseado no desenvolvimento sustentável, mas contraditoriamente, os indícios de ação conduzem à retórica do racionalismo econômico. Além disso, com a Rio+20 ficou patente a hipótese de submissão da natureza na interação com o homem, ou seja, o antropocentrismo; houve o esvaziamento da criticidade do status quo, não questionando, portanto, os fundamentos que dão sustentação à sociedade capitalista.

Segundo os autores, o conceito da economia verde serviu para fundamentar a racionalidade das Nações Unidas de que é possível existir crescimento econômico e proteção ambiental, concomitantemente, e por fim, durante todo o evento, nações e empresas protegeram-se contra proposituras onerosas, especialmente as que lidavam sobre direitos humanos e responsabilidades ambientais. Sendo a minimização das atribuições de responsabilidades futuras e seu financiamento a maior e principal decepção da Rio+20.

Portanto, o conceito da sustentabilidade do desenvolvimento, em sua trajetória histórica, tem sido exaustivamente teorizado, discutido e analisado, recebendo distintas classificações, denominações e qualificações, e longe se ser um conceito consensual e unânime entre os especialistas e instituições políticas. E são essas contrariedades e concepções antagônicas que têm marcado tanto as teorizações quanto as práticas da sustentabilidade ao redor do mundo, razão pela qual se propõe o aprofundamento desta temática.

\subsection{Outras notas a propósito da sustentabilidade}

Embora a literatura especializada majoritariamente aborde o Desenvolvimento Sustentável de natureza tridimensional - ambiental, social e econômica (BURSZTYN e BURSZTYN, 2006), (vide figura 1) há outras dimensões inerentes. O problema central da abordagem tridimensional não reside no fato das diferenciações existentes na literatura científica sobre cada uma dessas dimensões, mas que ao escolhê-las como elementares o faz no sentido de suprimir a dimensão do poder. Como se fosse possível mudar as estruturas de produção e padrões de consumo sem as decisões políticas e as instâncias de poder. O que ocorre é um processo de despolitização do Desenvolvimento Sustentável, como se a política não fosse relevante e necessária no processo de mudança (NASCIMENTO, 2012).

Dois pontos merecem destaque sobre a invisibilidade da politização da sustentabilidade, segundo Nascimento (2012): O primeiro alude ao processo de supressão do campo político nas discussões do Desenvolvimento Sustentável, ocor- 


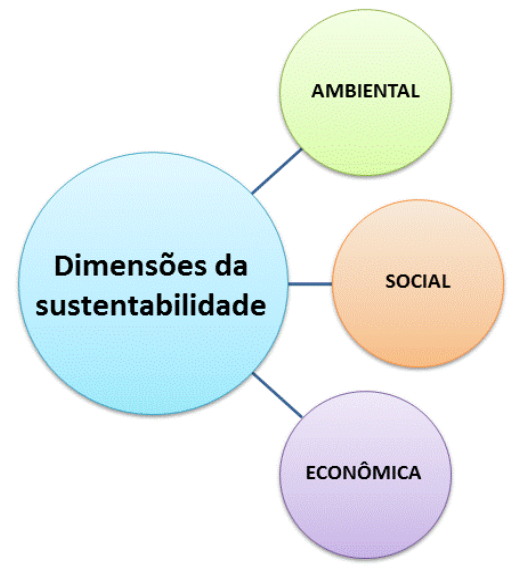

Figura 1: Dimensões clássicas da sustentabilidade do desenvolvimento

Fonte: Elaboração própria dos autores

rendo em parte pelo fato de que as discussões da sustentabilidade colocam no cerne interesses globais e não de classes e grupos sociais exclusivos, que possam aproveitar-se em detrimento de outrem. Outro toca ao descolamento do foco da transformação social via política e nas lutas sociais defendidas nos Séculos XVIII ao XX. Já em meados do século passado, a sociedade passa por uma série de metamorfoses sociais que substituíram a dimensão política pela social, especialmente pela produção de um mundo e economia globalizados, pelo surgimento de novos atores sociopolíticos planetários, reforçado pelo enfraquecimento do Estado-Nação e fortalecimento da economia cultural e simbólica e emergência de novas ciências e tecnologias. A questão, todavia, não se centra no uso da tecnologia uma vez que constitui um aspecto relevante, mas ao se tentar velar o caráter político da sustentabilidade, sobrepondo as mudanças via tecnologia, esquece-se que as transformações sociais devem passar imperativamente pelas decisões de espaços políticos e econômicos. Ao tratar sobre a sustentabilidade política, Stahel (1995) propõe como condição para um corpo societal sustentável uma recomposição política total da sociedade atual porque considera que essa dimensão foi destruída. Igualmente, em Lefebvre (1991), ao analisar o Terrorismo e Cotidianidade, temos uma propositura de uma revolução cultural permanente e total da sociedade que passa necessariamente pelos níveis econômicos, políticos e culturais.

A cultura constitui outro campo indispensável para o Desenvolvimento Sustentável, que não pode ser ignorado, mas que recorrentemente tem sido esquecida, pois não será possível uma mudança no estilo de vida e paradigma de consumo se não ocorrer uma mudança de valores e comportamentos, individuais e coletivos, que seria sair do ter mais para ter melhor e sair de consumir para usufruir. Em outras palavras, a sustentabilidade requer uma reforma moral e intelectual onde teria de ter ao invés de três dimensões, apresente cinco (NASCIMENTO, 2012), a saber, a econômica, ambiental, social, política e cultural.

$\mathrm{Na}$ mesma racionalização se situa Sachs (2004), ao indicar que o desenvolvimento sustentável deve contemplar cinco pilares: social, ambiental, territorial, econômica e política, conforme figura 2. E o faz sem negar a imprescindibilidade da dimensão cultural (SACHS, 2008).

A sustentabilidade social seria motivada por questões intrínsecas e instrumentais em face da problemática de disrupção societária presente em vários lugares do mundo. Quanto ao aspecto ambiental, deve contemplar duas dimensões de sistemas de sustentação da vida como provedores de recursos e depositário para o recebimento de resíduos. Outro se refere a uma melhor distribuição espacial dos recursos e das populações e das atividades econômicas entre os meios urbano e rural, de forma a evitar a excessiva concentração nas áreas urbanas. A sustentabilidade econômica seria a "[...] viabilidade econômica a conditio sine qua non para que as coisas aconteçam". O último, mas não menos importante, alude à sustentabilidade política, onde a governança democrática e a liberdade são peças fundamentais (SACHS, 2004, p. 15).

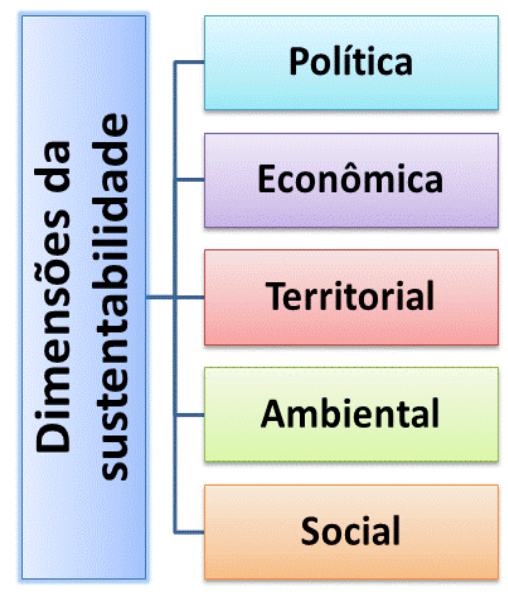

Figura 2: Dimensões ampliadas da sustentabilidade do desenvolvimento

Fonte: Elaboração própria dos autores 
A sustentabilidade é ainda uma questão ética. Para se atingir um desenvolvimento sustentável, além da implementação de medidas de política ambiental adequada, deve haver um sistema político e econômico estável que torne possível a participação de toda a sociedade (VIEDERMAN, 1993 apud PROOPS et al., 1997). Já Pereira (2008, p. 95) sugere a adoção do termo "controle democrático", que seria a soberania popular como vontade geral, em contraposição ao "controle social", formulado originalmente por Durkheim para expressar o controle do Estado sobre o povo. Uma nova ética econossocioambiental e participação social, assim como a reflexão sobre a quem de fato se destina a sustentabilidade, portanto, compõem elementos centrais nas discussões da sustentabilidade.

Outra questão alude ao divórcio entre Norte e Sul. A sustentabilidade é um desafio global e requer estratégias conjuntas e complementares entre Norte-Sul. O Norte com seu modelo de desenvolvimento demonstra-se insustentável. No Sul, ao reproduzir os padrões de consumo do Norte, em favor de segmentos minoritários, tem imputado um processo de apartheid social e degradação ambiental. O paradigma de desenvolvimento em curso precisa ser mudado. Mas a mudança deve ser iniciada pelo Norte e seguido pelo Sul (SACHS, 2008). Não pode haver duas sustentabilidades: uma do Norte e outra do Sul. As disparidades de acesso a tecnologias e a recursos ambientais, a assimetria da distribuição da riqueza socialmente produzida e a marcante ausência de formas de existências dignas intra e internacional são uma marca histórica da insustentabilidade da humanidade. $\mathrm{E}$ isto precisa ser superado se se quiser alcançar a sustentabilidade.

Afinal o desenvolvimento sustentável deve atender a um "duplo imperativo ético" alicerçado na "solidariedade com as gerações presentes e futuras", devendo apenas o desenvolvimento econômico, social e ambiental no mesmo nível e que seja mutuamente positivo receber a denominação de desenvolvimento sustentável (SACHS, 2004, p. 36). Em outras palavras, esse imperativo ético pode ser entendido como "solidariedade sincrônica" (geração atual) e "diacrônica" (geração futura), com vistas ao respeito e comprometimento com todas as formas de vida da Terra (SACHS, 2008, p. 49). Porém, o desenvolvimento sustentável pode também, apresentar uma dualidade de intenções: uma voltada para a ética e a outra com profundas caracterizações de dominação (RODRIGUES FILHO et al., 2009).

Uma retórica diz que o desenvolvimento sustentável deve ser entendido como o equilí- brio entre as três vertentes econômica, social e ambiental do desenvolvimento, contrapondo-se ao pensamento de se associar apenas a fatores de crescimento econômico, dada a mais que comprovada incapacidade deste modelo unívoco em atender aos anseios e necessidades humanas para o desenvolvimento pleno do ser social. Outros autores defendem que o desenvolvimento sustentável possui "[...] um caráter moderador ou apaziguador", diferentemente do ecologismo radical e da ecologia política, sendo ainda uma "proposta idealista" e utópica de desenvolvimento, que se demonstra fracassada por não haver objetivamente alcançado suas propostas, ficando meramente na retórica (JATOBÁ, CIDADE e VARGAS, 2009, p. 61-62).

Desta feita, o conceito de desenvolvimento sustentável para uns constitui como um campo dúbio e usual, "[...] é polissêmico" apresentando apreensões e leituras diversas, que vão desde a biologia até à economia (JATOBÁ, CIDADE e VARGAS, 2009, p. 62), "vazio" (STAHEL, 1995). Outros autores acrescentam que se trata de um conceito "recente" e que "[...] padece de ambiguidades e incertezas [...]", embora seja importante para leitura e enfrentamentos dos problemas globais (BURSZTYN e BURSZTYN, 2006, p. 55). A polissemia do termo é a demonstração de que a sustentabilidade representa um "[...] campo de forças, que passa a condicionar posições e medidas de governos, empresários, políticos, movimentos sociais e organismos multilaterais" (apud NASCIMENTO, 2012).

Ainda sobre os mais diversos entendimentos sobre o desenvolvimento sustentável, enquanto Redclift (1987) o apreende como uma ideia poderosa, Richardson (1997) o considera fraude, uma vez que intenciona encobrir a incongruência entre a limitação dos recursos ambientais e a natureza desenvolvimentista da sociedade urbano-industrial (NASCIMENTO, 2012). Já na concepção de Sachs (2008), a sustentabilidade do desenvolvimento requer fundamentalmente a apropriação efetiva dos direitos humanos, sociopolíticos, culturais e econômicos, bem como ao direito societário em relação ao meio ambiente e seus recursos. Trata-se de um desafio planetário complexo.

[...] O desenvolvimento sustentável é um projeto social e político que aponta para o ordenamento ecológico e descentralização territorial da produção, assim como para a diversificação dos tipos de desenvolvimento e dos modos de vida das populações que habitam o planeta. Neste sentido, oferece novos princípios aos processos de demo- 
cratização da sociedade que conduzem à participação direta das comunidades na apropriação e transformação de seus recursos ambientais (LEFF, 2005, p. 57).

Apesar de a sustentabilidade ter apreensões diversas e antagônicas e sem perder de vista a criticidade na leitura de nossa sociedade, adere-se ao entendimento do Desenvolvimento Sustentável como um novo valor, vinculando-o às prospecções de um novo modelo de desenvolvimento com respeito a todas as formas de vida, ou seja, o surgimento de outra racionalidade que leve em conta questões de prudência ambiental, eficiência econômica atrelada à justiça social no processo de desenvolvimento, que contemple ao mesmo tempo a tríade da sustentabilidade: as esferas econômica, social e ambiental, sem, contudo, desprezar o campo político-cultural.

Os pensamentos da ecologia radical, que defendiam a sobreposição dos aspectos naturais sob os aspectos socioeconômicos, foram relevantes para o surgimento de uma consciência ambiental, no entanto mostrou-se "[...] pouco simpática aos esforços políticos que buscavam uma aproximação entre objetivos econômicos, ecológicos e sociais [...]" (JATOBÁ, CIDADE e VARGAS, 2009, p. 55). Em outras palavras, não se pode considerar a sustentabilidade levando apenas em consideração um aspecto - a natureza -, nem tampouco fixá-la numa âncora econômica, mas importa considerar o papel fundamental das atividades humanas nesse processo, quer no campo econômico e/ou no contexto sociopolítico.

Os 4 bilhões de excluídos dos "benefícios da globalização" (vitimizados pelo drama de distribuição desigual de renda, riqueza e oportunidades dignas de inserção produtiva) e "[...] um PIB que cresce mas não inclui as populações não é sustentável. Estamos falando de quase dois terços da população mundial a quem se trava o acesso ao financiamento, às tecnologias, ao direito de cada um ganhar o pão da sua família". O PIB que não colabora para o melhoramento da qualidade de vida da maioria das populações, e isto, portanto, não se resume apenas à vida material do homem, uma vez que este se constitui de múltiplas faculdades que requerem a sua conjugada atenção e satisfação, já se mostra fracassado e por isso mesmo inviável (DOWBOR, SACHS e LOPES 2010, p. 138).

Nesse sentido, o Produto Interno Bruto

[...] apenas indica o fluxo de bens e serviços produzidos pela atividade humana, jamais o total de riquezas disponíveis. Essa distinção se torna ainda mais importante se considerarmos que o que caracteriza a produção humana é justamente uma série de externalidades negativas, cujo custo em termos de bem-estar frequentemente suplanta o seu valor. É essa mercantilização crescente da sociedade moderna, às custas dos equilíbrios naturais, das relações sociais e da autonomia individual, que tem de ser revista, antes de tudo, se quisermos pensar em uma sociedade sustentável e, mais do que isso, se nossa preocupação não se limita a uma simples questão de sobrevivência física, mas sim a uma busca constante de qualidade de vida (STAHEL, 1995, p. 124).

Vale salientar que a qualidade de vida representa um conceito central nas discussões e objetivações da gestão ambiental, surgindo num momento de profundo consumismo e concentração de abundância produzida, degradação ambiental, dentre outros. A ênfase nos processos qualitativos das condições de vida explicitam degradação do ambiente, dos instrumentos e serviços públicosociais básicos e do igualitário acesso ao consumo, bem como da própria condição humana acerca da atenção de suas necessidades elementares. $\mathrm{Na}$ contramão da homogeneização da produção e satisfação das necessidades sociais deturpadas, surge a qualidade de vida que deverá está antenada com as multivariadas particularidades e circunstâncias que repercutem sobre o individuo e sobre a sociedade.

A globalização, entendida como fenômeno composto de variadas dimensões e com graves implicações políticas, econômicas, sociais, ambientais e culturais, não se apresenta uniforme e nem beneficia a todos os cidadãos dos Estados Nacionais inseridos nesse processo, uma vez que algumas nações avançam mais celeremente, enquanto que regiões inteiras ficam para trás, ou seja, atrasadas em muitos aspectos. Essa diferenciação estrutural e assimétrica de integração pode representar e explicar outra diferença a ser adicionada entre países industrializados do Primeiro Mundo e os países pobres e atrasados do Terceiro-Mundo (SANTANA, 1999). Referindo-se a algumas contradições existentes no desenvolvimento sustentável, Kitamura (1994) vai afirmar que é equívoco pensar o mercado como um bom mediador nos processos de manejo dos problematizações ecológicas, quer para os países ditos industrializados ou mesmo para os países do Terceiro-Mundo ou pobres. A hiperacumulação do paradigma societário de 
desenvolvimento industrial e tecnológico atual põe em xeque a vida humana, assim como de todas as outras formas de vida, igualmente relevantes no processo de sustentabilidade.

É essa impossibilidade de consideração de outras vertentes que transcendam os curtos prazos e a lucratividade e alocação de recursos nos moldes smithiano que demonstra a miopia e cegueira dos mercados econômicos globais, bem como a nítida insustentabilidade do desenvolvimento sustentável global vigente (SACHS, 2008). A questão da adoção de novos modelos e instrumentos de organicidade planetária, novo contrato social e ambiental, a serem concebidos por distintos povos converteu-se numa necessidade urgente. As relações, agendas diplomáticas, acordos e intercâmbios entre países centrais e periféricos precisam ser reformulados, para que ambos tenham aproximação mais fraterna e equânime (FREITAS, 2004).

Portanto, a sustentabilidade do desenvolvimento está associada a uma complexidade social, econômica e política construída nas múltiplas formas de domínio e de poder na sociedade moderna. Esse processo constitutivo influencia profundamente as condições humanas de vida, os sistemas ecológicos, as diversas formas de vida existentes na Nave Terra, assim como constitui uma das mais instigantes questões civilizacionais do mundo.

\section{CONSIDERAÇÕES FINAIS}

O objetivo principal da sustentabilidade, portanto, é a construção de uma cidadania possibilitadora de melhores condições de vida à humanidade, bem como o respeito a outras formas de vida igualmente importantes para a Gaia, conforme proposto por Lovelock (2006), incluindo-se a supressão da miséria, pobreza e desigualdade humana e a aniquilação da sociobiodiversidade.

Encontros internacionais para tratar da temática ambiental e aprofundar acordos internacionais são cada vez mais frequentes e maiores, como a recente Conferência das Nações Unidas sobre Desenvolvimento Sustentável, a Rio+20, ocorrida no Rio de Janeiro. No entanto, as empreitadas da sustentabilidade do desenvolvimento esbarram na racionalidade de mercado e na teoria econômica do crescimento sem limites, da produção e consumo exacerbados de recursos ambientais, comprometendo os avanços significativos neste campo de embate político. Das diversas alternativas que se possa vislumbrar para a resolução dessa questão, uma parece nítida e necessária: a mudança global de uma racionalidade fundada em valores econômicos e consumistas, na desigualdade, miséria e na degradação e opressão humana e desrespeito a outras formas de vida planetárias; e a adoção de valores humanitários orientados pela solidariedade entre os povos (via novo contrato socioecológico), negando a mediação destrutiva de capital imposta pela globalização, conforme a sugestão de Santos (2001).

Para a sustentabilidade, que contempla as dimensões social, cultural, ambiental, territorial, econômica e política (SACHS, 2008) e para as questões complexas envolvendo a sociedade em curso, não existem resoluções fáceis. Porém, a seriedade das questões socioambientais obriga aos habitantes da Nave Terra uma resposta premente, sem a qual haveremos de ver aos nossos olhos todas as formas de vida agonizando num irrevogável processo racional degradativo antropogênico e entrópico. Com a crise socioambiental global surgiu a necessidade de resolução da problemática, como fim planetário central, e esta encruzilhada histórica por que passa a humanidade longe de apresentar uma via resolutiva fácil, mostra-se como um dos mais sérios dilemas a serem enfrentados na modernidade, no qual todos, indistintamente, têm papel fundamental para a consecução da sustentabilidade intra e intergeracional mundial, de modo que os atuais padrões de vida fundados no consumismo, na depleção e degradação ambiental sejam substituídos por outra via de desenvolvimento com equidade social, justiça ambiental e qualidade de vida.

\section{AGRADECIMENTOS:}

Ao Conselho Nacional de Desenvolvimento Científico e Tecnológico - CNPq.

\section{REFERÊNCIAS}

BURSZTYN, M. A. A.; BURSZTYN, M. Desenvolvimento sustentável: biografia de um conceito. In: NASCIMENTO, E. P. do; VIANNA, J. N. S. (Orgs.). Economia, meio ambiente e comunicação. Rio de Janeiro: Garamond, 2006.

DOWBOR, L.; SACHS, I.; LOPES, C. Crises e oportunidades em tempos de mudança. Economia global e gestão, v. XIV, p. 133-154, 2010.

CMMAD. Nosso futuro comum. 2. ed. Rio de Janeiro: Fundação Getúlio Vargas, 1991. 
FREITAS, M. de. Nuanças da sustentabilidade: visões fantásticas da Amazônia. Caderno do Centro de Estudo e Ação Social (CEAS), São Paulo, n. 207, set/out. 2003.

Amazônia e desenvolvimento sustentável: um diálogo que todos brasileiros deveriam conhecer. Colaboração de Walter Esteves de Castro Júnior. Petrópolis, RJ: Vozes, 2004.

JATOBÁ, S. U. S.; CIDADE, L. C. F.; VARGAS, G. M. Ecologismo, ambientalismo e ecologia política: diferentes visões da sustentabilidade e do território. Sociedade e Estado. Brasília, v. 24, n. 1, p. 47-87, jan./abr. 2009.

KITAMURA, P. C. A Amazônia e o desenvolvimento sustentável. Brasília: EMBRAPA-SPI, 1994.

LEFEBVRE, H. A vida cotidiana no mundo moderno. São Paulo: Ática, 1991.

LEFF, E. Racionalidade ambiental, produtividade ecotecnológica e manejo integrado de recursos. In:

LEFF, E. Ecologia, capital e cultura: racionalidade ambiental, democracia participativa e desenvolvimento sustentável. Tradução Jorge Esteves da Silva. Blumenau: Editora FURB, 2000.

Saber ambiental: sustentabilidade, racionalidade, complexidade, poder. Tradução de Lúcia Mathilde Endlich Orth. 4. ed. Petrópolis, RJ: Vozes, 2005.

LOVELOCK, J. Prefácio: algo de sórdido na estufa e Introdução. In: LOVELOCK, J. Gaia: cura para um planeta doente. Tradução Aleph Teruya Eichemberg e Newton Roberval Eichemberg. São Paulo: Cultrix, 2006.

MAIA FILHO, R. G. Conflito entre as determinações da Convenção sobre Diversidade Biológica e as regras do Acordo TRIPS. Brasília: FUNAG, 2010.

NASCIMENTO, E. P. do. Trajetória da sustentabilidade: do social ao ambiental, do ambiental ao econômico. Estudos Avançados (USP. Impresso), v. 26, p. 51-64, 2012.

PEREIRA, P. A. P. Discussões conceituais sobre política social como política pública e direito de cidadania. In: BOSCHETTI, I et al. (Orgs.). Política social no capitalismo: tendências contemporâneas.
São Paulo: Cortez, 2008.

PROOPS, J. et al. Realizando um mundo sustentável e o papel do sistema político na consecução de uma economia sustentável. In: CAVALCANTI, C. (Org.) Meio ambiente, desenvolvimento sustentável e políticas públicas. São Paulo: Cortez; Recife: Fundação Joaquim Nabuco, 1997.

RODRIGUES FILHO, S. et al. Uma análise sobre indicadores de sustentabilidade e seus conceitos operacionais. In: PEREIRA, $\mathrm{H}$. dos $\mathrm{S}$. et al. Pesquisa interdisciplinar em ciências do meio ambiente. Manaus: Edua, 2009.

ROMEIRO, A. R. Desenvolvimento Sustentável: uma perspectiva econômico-ecológica. Estudos Avançados (USP. Impresso), v. 26, n. 74, p. 65-92, 2012.

SACHS, I. Desenvolvimento: includente, sustentável e sustentado. Rio de Janeiro: Garamond, 2004.

Caminhos para o desenvolvimento sustentável. 3. ed. Rio de Janeiro: Garamond, 2008.

SANTANA, G. M. Como funciona a globalização. Manaus: Valer, 1999.

SANTOS, Milton. Por uma outra globalização: do pensamento único à consciência universal. 6. ed. Rio de Janeiro: Record, 2001.

SILVA, P. C. S. ; DIAS, V. B. As mudanças climáticas na região amazônica e sua repercussão no direito internacional ambiental. Revista C@LEA, v. 1, n, 1, p. 20, 2012.

STAHEL, A. W. Capitalismo e entropia: os aspectos ideológicos de uma contradição e a busca de alternativas sustentáveis. In: CAVALCANTI, C. (Org.) Desenvolvimento e natureza: estudos para uma sociedade sustentável. São Paulo: Cortez, 1995.

WENCESLAU, J.; ANTEZANA, N. L.; CALMON, P. du P. Políticas da Terra: existe um novo discurso ambiental pós Rio+20?. Políticas da Terra: existe um novo discurso ambiental pós Rio +20 ? . Cadernos EBAPE.BR (FGV), v. 10, p. 584-604, 2012. 